\title{
Interferência de Plantas Daninhas em Diferentes Densidades no CRescimento da SoJA ${ }^{1}$
}

\author{
Interference of Different Weed Densities in Soybean Growth
}

\author{
SILVA, A.F. ${ }^{2}$, CONCENÇO, G. ${ }^{2}$, ASPIAZÚ, I. ${ }^{2}$, FERREIRA, E.A. ${ }^{2}$, GALON, L. ${ }^{2}$, COELHO, A.T.C.P. ${ }^{3}$, \\ SILVA, A.A. ${ }^{4}$ e FERREIRA, F.A. ${ }^{4}$
}

\begin{abstract}
RESUMO - Este trabalho foi realizado com o objetivo de avaliar os efeitos de densidades de plantas daninhas (baixa, média e alta infestação) sobre as variáveis de crescimento da soja, cv. BRS 243-RR. O delineamento experimental foi de blocos ao acaso, sendo os tratamentos constituídos por dez períodos de convivência das plantas daninhas com a cultura (0, 0-5, 0-10, 0-15, 0-21, 0-28, 0-35, 0-42, 0-49 e 0-125 dias). As variáveis estudadas foram altura de plantas, massa seca dos ramos desprovidos de folha, massa seca das folhas, número de folhas e área foliar da soja. As avaliações foram determinadas no final do periodo de interferência, juntamente com a avaliação de densidade e acúmulo de fitomassa da comunidade infestante. Na área onde a soja foi cultivada sob baixa infestação de plantas daninhas, observou-se aumento da densidade das infestantes em função do tempo após a emergência da soja. Todavia, o contrário foi observado nas áreas de média e alta infestação; nelas verificou-se redução da densidade das plantas daninhas ao longo do período de avaliação. A altura e área foliar das plantas de soja foram influenciadas pelo nivel de infestação, o que não foi observado para massa seca e número de folhas. Conclui-se que o nivel de infestação afeta de maneira diferenciada as variáveis que definem o crescimento da soja.
\end{abstract}

Palavras-chave: Glycine max, competição, planta daninha.

ABSTRACT - This work was carried out to evaluate the effects of weed densities (low, average and high infestation) on the growth of soybean, $c v$. BRS-243RR. The experiment was arranged in a completely randomized block design, with the treatments being the periods of competition between the culture and the weeds $(0,0-5,0-10,0-15,0-21,0-28,035,0-42,0-49$ and $0-125$ days). The variables evaluated were plant height, dry mass ofleaves and branches, number ofleaves and leaf area. These evaluations were conducted at the end of each interference period together with weed density and mass accumulation evaluations. When weeds were under low density, a great increase in its density was observed along time, in contrast to the observed under average and high infestation levels, when weed density decreased as a function of days after emergence. Soybean plant height and leaf area were influenced by infestation level but dry mass and number of leaves were not .It was concluded that the level of infestation affects differently the variables that define soybean growth.

Keywords: Glycine max,competition, weed.

\section{INTRODUÇÃO}

A competição de plantas daninhas com a cultura da soja pode se refletir em perdas relevantes na produtividade de grãos. Em ecossistemas agrícolas, a cultura e as plantas daninhas possuem suas demandas por água, luz, nutrientes e $\mathrm{CO}_{2}$ e, na maioria das vezes, um ou mais desses fatores de crescimento estão disponiveis em quantidade insuficiente até mesmo para o próprio desenvolvimento da cultura - estabelece-se, assim, a competição (Radosevich et al., 1997). No entanto, por ser uma espécie que apresenta características de plasticidade, a soja mostra respostas adaptativas às condições ambientais e ao manejo em que se desenvolve (Melges et al., 1989).

1 Recebido para publicação em 10.12.2007 e na forma revisada em 18.2.2009.

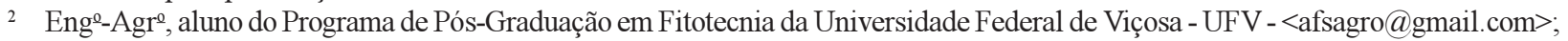
${ }^{3}$ Estudante de graduação em Agronomia da UFV; ${ }^{4}$ Engo--Agr ${ }^{0}$, D. Sc. Professor do Dep. de Fitotecnia da UFV (Bolsista do CNPq). 
A soja é menos eficiente na extração de água do solo do que algumas plantas daninhas (Procópio et al., 2005), porém apresenta maior eficiência no uso da radiação (UER), ou seja, maior quantidade de biomassa acumulada por unidade de radiação captada, que Euphorbia heterophylla, Bidens pilosa e Desmodium tortuosum (Santos et al., 2003). Esses autores afirmam que, apesar de as plantas daninhas avaliadas apresentarem menor eficiência no uso da radiação fotossinteticamente ativa, elas mostram grande capacidade competitiva em campo, em razão de a população ser maior e da melhor utilização de outros recursos, como água e nutrientes.

Quando plantas de soja estão sob competição, o seu comportamento é dependente da densidade da cultura e da planta daninha, da espécie infestante e das condições ambientais supracitadas, como radiação, umidade e nível de nutrientes no solo. De maneira geral, sob competição, as plantas da cultura tendem a incrementar sua altura, como forma de maximizar a captação da radiação e sombrear as plantas daninhas; o acúmulo de massa seca é reduzido, bem como a área foliar e a relação folhas/ramos. Além disso, alguns índices são normalmente alterados, como a razão de área foliar e a área foliar específica, que auxiliam na descrição do comportamento das plantas sob competição. Todo o estresse causado à cultura tende a refletir em alterações morfofisiológicas nas plantas, com reflexo na produtividade (Lamego et al., 2005).

Os efeitos negativos da comunidade infestante em culturas decorrem tanto do aumento na densidade de plantas daninhas quanto da duração do período de interferência (Ghersa \& Holt, 1995). O incremento na densidade de plantas daninhas aumenta as perdas de rendimento em arroz irrigado (Vandevender et al., 1997). O grau de interferência exercido por plantas daninhas dicotiledôneas na cultura da soja depende da espécie daninha presente e de sua densidade (Rizzardi et al., 2003). Além da densidade de plantas daninhas, o período de convivência entre a cultura e as plantas daninhas define o nível de danos à cultura. Como regra geral, quanto maior o período de convivência da cultura com as plantas daninhas, maior o prejuízo ao rendimento de grãos, pela redução das variáveis de crescimento, como número de folhas, área foliar e massa seca das plantas de soja. Esse conceito está associado ao período crítico de prevenção à interferência, estabelecido por Pitelli (1985).

Objetivou-se com este trabalho avaliar os efeitos do período de convivência e do nível de infestação por plantas daninhas na cultura da soja sobre as variáveis de crescimento.

\section{MATERIAL E MÉTODOS}

O experimento foi realizado nos sistemas de plantio convencional e direto em Argissolo Vermelho-Amarelo câmbico, no período de novembro de 2006 a março de 2007, em CoimbraMG. O plantio direto foi realizado em área já cultivada com este sistema de plantio por sete anos. A área de baixa infestação correspondeu ao sistema de plantio direto; as áreas de média e alta infestação foram conduzidas em sistema convencional de semeadura. Dez dias após a emergência (DAE) da soja, as áreas de baixa, média e alta infestação apresentavam, respectivamente, densidade média de 0-30, 31-150 e mais de150 plantas daninhas por metro quadrado. A análise das amostras de solo, coletadas antes da instalação do experimento na área destinada ao plantio convencional, apresentou as seguintes características químicas: $\mathrm{pH}$ em água de 5,0; 1,01 dag $\mathrm{kg}^{-1}$ de matéria orgânica; 9,6 mg dm $\mathrm{me} \mathrm{P}^{3} 50 \mathrm{mg} \mathrm{dm}^{-3}$ de $\mathrm{K}$; e Ca, $\mathrm{Mg}, \mathrm{H}$ + Al e CTC de 2,0;0,5; 2,5; e 5,12 $\mathrm{cmol}_{\mathrm{c}} \mathrm{dm}^{-3}$, respectivamente. Em plantio direto, os valores corresponderam a $\mathrm{pH}$ em água de 5,0; $1,07 \mathrm{dag} \mathrm{kg}^{-1}$ de matéria orgânica; $7,1 \mathrm{mg} \mathrm{dm}^{-3}$ de P; $59 \mathrm{mg} \mathrm{dm}^{3}$ de $\mathrm{K}$; e Ca, $\mathrm{Mg}, \mathrm{H}+\mathrm{Al}$ e CTC de 2,$3 ; 0,6 ; 2,6$; e $5,65 \mathrm{cmol}_{\mathrm{c}} \mathrm{dm}^{-3}$, respectivamente.

Antecedendo à instalação dos ensaios, foi realizada a dessecação química com os herbicidas glyphosate e 2,4-D (1.440 g + $470 \mathrm{~g} \mathrm{ha}^{-1}$, respectivamente) em mistura no tanque, dez dias antes da semeadura. Os produtos comerciais utilizados foram Roundup Original ${ }^{\circledR}$ e $\mathrm{DMA}^{\circledR}$. No ensaio referente ao plantio convencional, essa vegetação foi incorporada pelo preparo mecânico do solo com uma aração e duas gradagens, sete dias antes da semeadura, enquanto no plantio direto a palhada permaneceu na superficie do solo. O cultivar de soja utilizado foi o BRS 243-RR, semeando-se 13,5 sementes por metro, no espaçamento de 
$0,50 \mathrm{~m}$ entre linhas. A adubação foi vista com $400 \mathrm{~kg} \mathrm{ha}^{-1}$ da formulação 8-28-16 (N-P-K) na linha de plantio. Os dados climatológicos do período de condução do ensaio estão apresentados na Figura 1.

Em ambos os sistemas de cultivo a cultura da soja ficou em convivência com as plantas daninhas por diferentes períodos do seu ciclo de desenvolvimento: $0,5,10,14,21,28,35$, 42,49 e 125 dias (todo o ciclo da cultura), totalizando assim dez tratamentos em cada nivel de infestação. Após o término de cada período inicial de convivência, foi realizado o controle das plantas daninhas até a colheita, com aplicações de glyphosate $\left(720 \mathrm{~g} \mathrm{ha}^{-1}\right)$ sempre que necessário, para manter as parcelas livres de infestação. O delineamento experimental foi de blocos casualizados, com dez tratamentos e quatro repetições. As parcelas foram constituídas por seis linhas de $3,0 \mathrm{~m}$ de comprimento. A área útil para avaliação foi constituída pelas quatro linhas centrais.

As avaliações da densidade e da matéria seca das plantas daninhas foram realizadas no final de cada período de convivência. Essas avaliações foram feitas com o lançamento aleatório de quadrado metálico de 0,25 m de lado, por quatro vezes, na área útil de cada parcela. As partes aéreas das plantas daninhas foram coletadas e separadas por espécie, determinando-se os valores de densidade e massa seca. A massa seca foi obtida pela secagem em estufa com ventilação forçada de ar a $70{ }^{\circ} \mathrm{C}$, até massa constante.

Para avaliar a altura das plantas, massa seca dos ramos desprovidos de folha, massa seca das folhas, número de folhas e área foliar, foram colhidas ao acaso dez plantas na área útil de cada parcela, no dia correspondente ao tratamento especificado. A altura média foi obtida com auxílio de régua graduada $\mathrm{em} \mathrm{mm}$, desde a base da planta até o último nó desenvolvido no caule. O número de folhas foi determinado por contagem manual, sendo consideradas as folhas unifolioladas e trifolioladas. Para obtenção da área foliar e da massa seca de ramos e folhas, oito plantas na área útil de cada parcela foram colhidas ao acaso no dia correspondente aos tratamentos. As plantas foram cortadas rente ao solo e armazenadas em sacolas plásticas, vedadas e identificadas adequadamente, acondicionadas

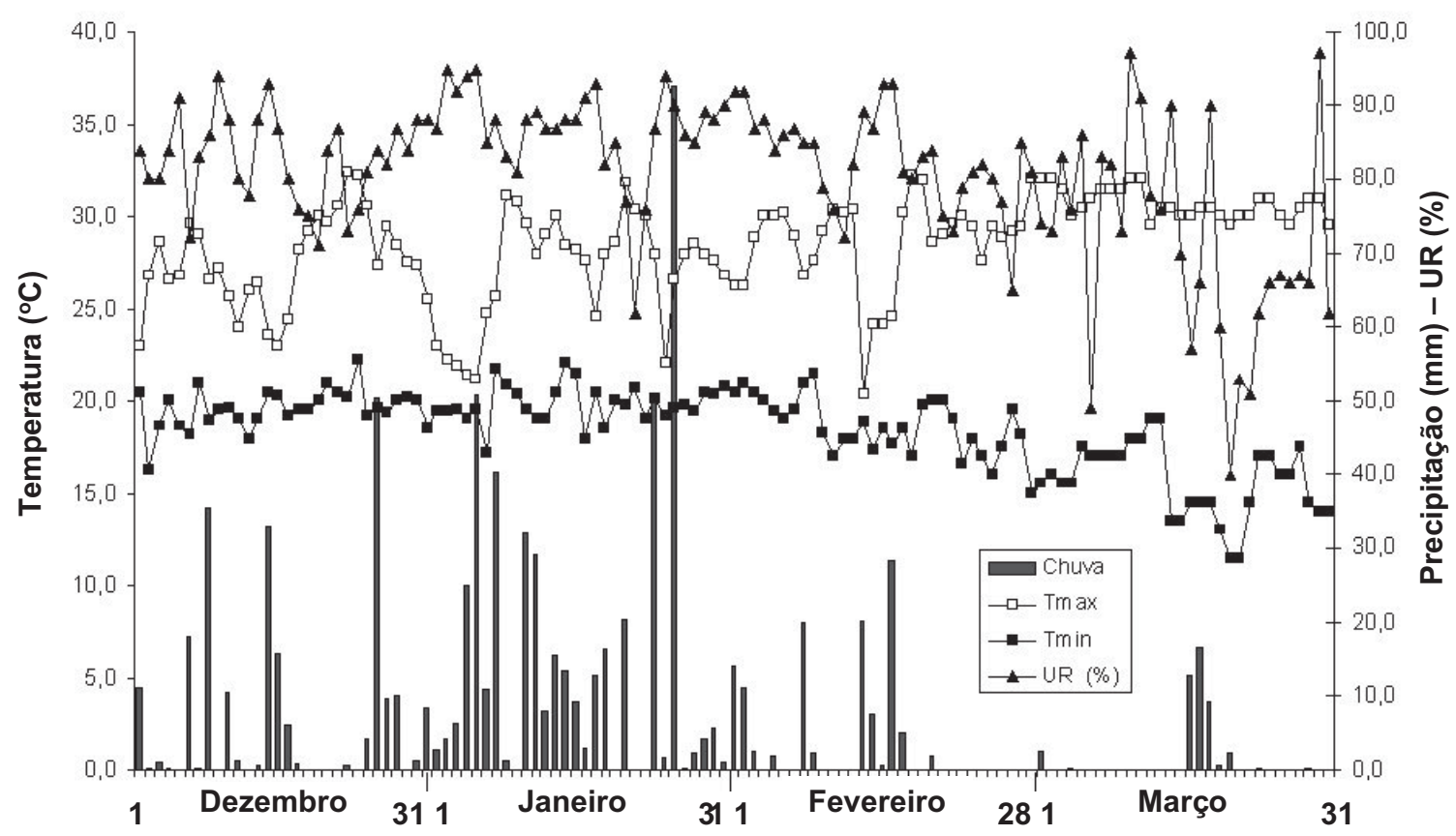

Figura 1 - Dados climáticos observados na área experimental durante a realização do experimento: precipitação pluvial, temperaturas máxima e mínima e umidade relativa do ar. 
em caixa de poliestireno expandido (Isopor ${ }^{\mathbb{R}}$ ) com gelo, sendo posteriormente levadas para o laboratório. Posteriormente, as plantas foram separadas em caule e folhas. As folhas foram fotografadas à distância padronizada, e a área foliar, determinada por meio do software ImagePro Plus 5.1. Para obtenção da massa seca, o material foi colocado em sacos de papel, contendo separadamente folhas e caules, e posteriormente em estufa com ventilação forçada de ar a $70{ }^{\circ} \mathrm{C}$, até atingir massa constante.

Todos os dados foram verificados quanto à normalidade e homogeneidade e submetidos à análise de variância pelo teste $\mathrm{F}$. Em caso de significância, os dados foram submetidos à análise de regressão. Foi elaborada ainda matriz de correlação de Pearson entre as variáveis estudadas.

\section{RESULTADOS E DISCUSSÃO}

Analisando os períodos de convivência das plantas daninhas com a soja, em área de baixa infestação (Figura 2-A), verificou-se aumento linear na densidade de plantas ao longo dos períodos de avaliação. Isso decorreu da baixa densidade de plantas infestantes na área, não caracterizando a competição inter e intraespecífica por espaço. Essa menor densidade pode ser atribuída ao sistema de semeadura direta, que é caracterizado pelo menor revolvimento do solo e pela presença de restos culturais sobre a superficie deixada pela cultura anterior por ocasião da colheita ou pela dessecação e/ ou rolagem da cobertura vegetal. Esse fator exerce forte influência física, química e biológica sobre a germinação das plantas daninhas, provocando alterações na dinâmica do banco de sementes do solo e influenciando a quebra da dormência, a germinação e a ação dos microrganismos (Buzatti, 1999; Silva et al., 2005).

$\mathrm{Na}$ área de média (Figura 2-B) e alta (Figura 2-C) infestação, observou-se decréscimo na densidade da comunidade infestante a partir de 33 e 28 dias após a emergência (DAE), respectivamente. Isso decorreu da mortalidade de plantas devido à alta densidade de espécies daninhas presentes nas áreas, promovendo competição mais acirrada pelos recursos do meio. No sistema convencional de semeadura, o preparo do solo pode promover a disseminação de algumas espécies de plantas que se propagam vegetativamente, proporcionando altas infestações (Jakelaitis et al., 2003).
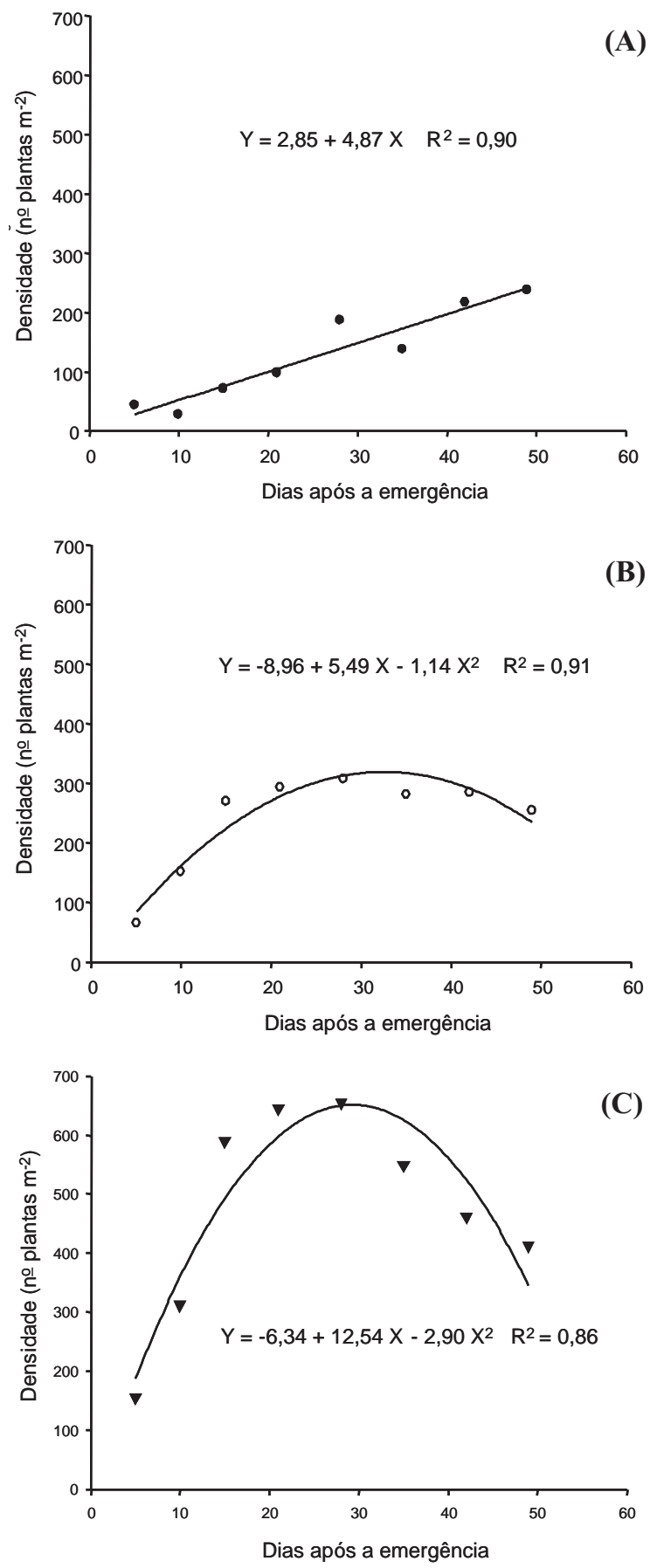

Figura 2 - Densidade da comunidade infestante em diferentes épocas após a emergência da soja cultivada em áreas de baixa (A), média (B) e alta infestação (C) de plantas daninhas. 
A comunidade infestante se mostrou diferente de acordo com o sistema de cultivo adotado. Na área de baixa infestação, a principal espécie infestante foi Brachiaria plantaginea, responsável por $80 \%$ da massa seca total produzida pelas plantas nesse nivel de infestação. Nas áreas de média e alta infestação, as principais espécies infestantes foram $B$. plantaginea e Cyperus rotundus, sendo responsáveis por 60,23 e $31,38 \%$, respectivamente, da massa seca total produzida em média infestação e por 53,22 e $37,60 \%$, respectivamente, da massa seca total produzida na área de alta infestação.

A ocorrência de $C$. rotundus, observada no plantio convencional, pode ser atribuída ao revolvimento do solo, cujo efeito sobre essa espécie favorece sua propagação e seu estabelecimento (Godoy et al., 1995; Ferreira et al., 2000). O revolvimento do solo pode separar o

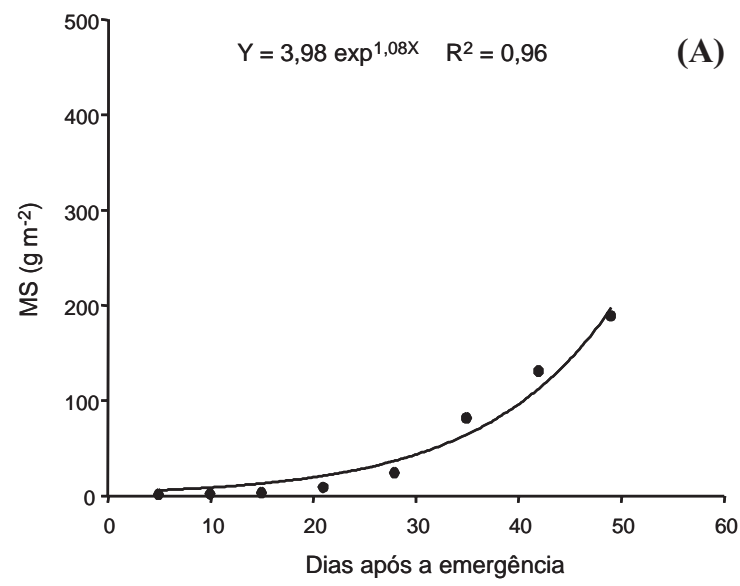

(A)

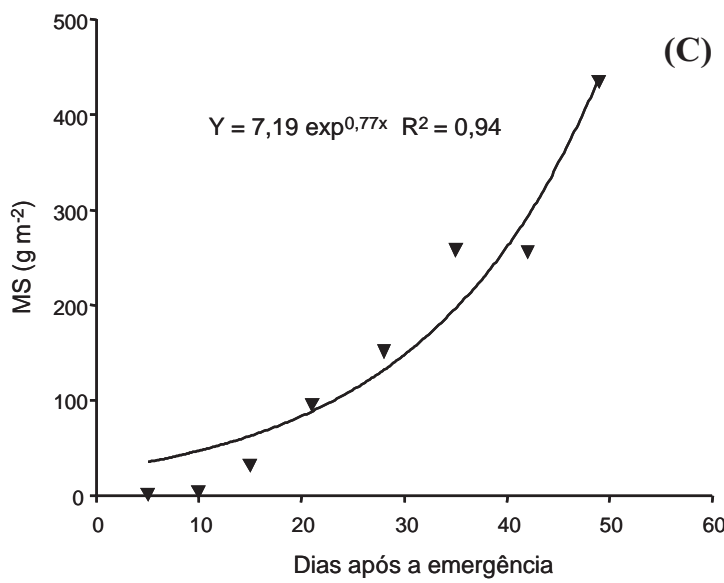

Figura 3 - Massa seca (MS) da comunidade infestante em diferentes épocas após a emergência da soja cultivada em áreas de baixa (A), média (B) e alta infestação(C) de plantas daninhas. tubérculo dos rizomas, reduzindo a dormência e favorecendo a germinação (Jakelaitis et al., 2003).

Na Figura 3 são apresentados os resultados de massa seca acumulada pela comunidade infestante, em função dos períodos iniciais de convivência nos diferentes niveis de infestação. Nas áreas experimentais de média e alta infestação, observou-se que, apesar da redução nas densidades de plantas ocorrida ao longo do período de avaliação, houve aumento da massa seca da comunidade infestante. Segundo Radosevich et al. (1997), à medida que aumenta a densidade e ocorre o desenvolvimento das plantas daninhas, especialmente daquelas que germinaram e emergiram no início do ciclo da cultura, intensifica-se a competição inter e intraespecífica, de modo que as plantas daninhas mais altas e desenvolvidas

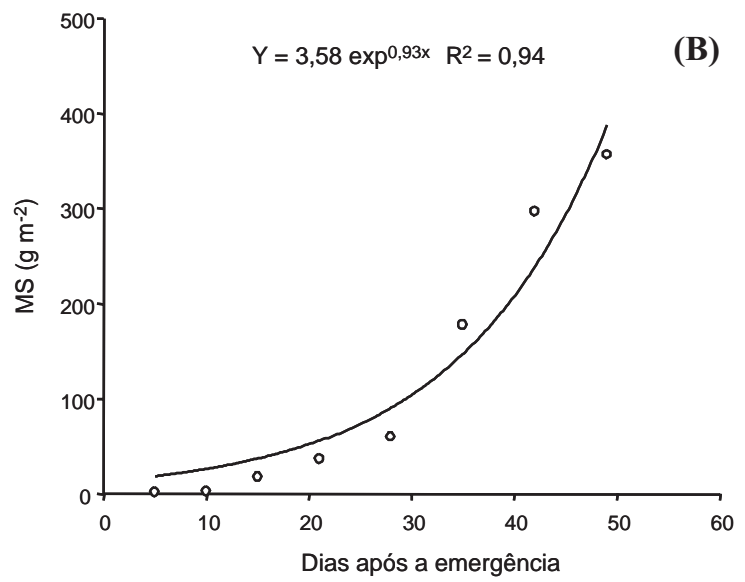

(C) 
tornam-se dominantes, ao passo que as menores podem ser suprimidas ou morrem. Esse comportamento de uma comunidade infestante explica a redução da densidade de plantas com o aumento da massa seca durante o desenvolvimento da cultura.

Quanto à altura da soja (Figura 4), observou-se que houve relação entre o nivel de infestação e essa variável ao longo do ciclo. Esse resultado pode ser atribuído a alterações na qualidade e intensidade da luz incidente sobre as plantas de soja, que irão afetar o desenvolvimento das plantas cultivadas (Ballare $\&$ Casal, 2000). Morfologicamente, plantas de uma cultura serão mais altas quanto maior for a competição com as plantas daninhas, mesmo que a competição ainda não tenha atingido niveis críticos. Plantas da comunidade infestante refletem luz em determinado comprimento de onda, o que normalmente é reconhecido pelas plantas da cultura, que estimulam o crescimento em altura mesmo antes da imposição de competição, como forma de captar o máximo da radiação disponível e sombrear as plantas daninhas (Radosevich et al., 1997). Esse efeito depende da qualidade da luz recebida, da planta da cultura e da composição da comunidade infestante.

A variação na qualidade da luz é percebida por pigmentos (fitocromos, criptocromo e fitotropina) mesmo antes de ocorrer o sombreamento e objetiva ajustar o crescimento da planta em função da presença de vizinhos (Taiz \& Zeiger 2004). A relação da radiação vermelho/vermelho distante, percebida principalmente pelos fitocromos, tem papel importante na indução de muitas alterações morfológicas na arquitetura das plantas, como incremento na proporção de acúmulo de massa em caule (Ballare \& Casal, 2000). Além de alterações na relação folhas/colmos, o sombreamento das plantas, detectado pela elevada incidência da luz vermelho distante, faz com que elas aloquem maior disponibilidade de recursos para investimento no crescimento da parte aérea, normalmente afetando o desenvolvimento do sistema de raízes e, com isso, podendo comprometer a disputa por recursos do solo (Rajan \& Swanton, 2001).

Apesar dos diferentes niveis de infestação, a soja mostrou a mesma capacidade de acúmulo de matéria seca ao longo do período de avaliação (Figuras 5, 6 e 7). Radosevich et al. (1997) explicam que, em densidade muito baixa, o rendimento da população é determinado pelo número de indivíduos. Conforme a
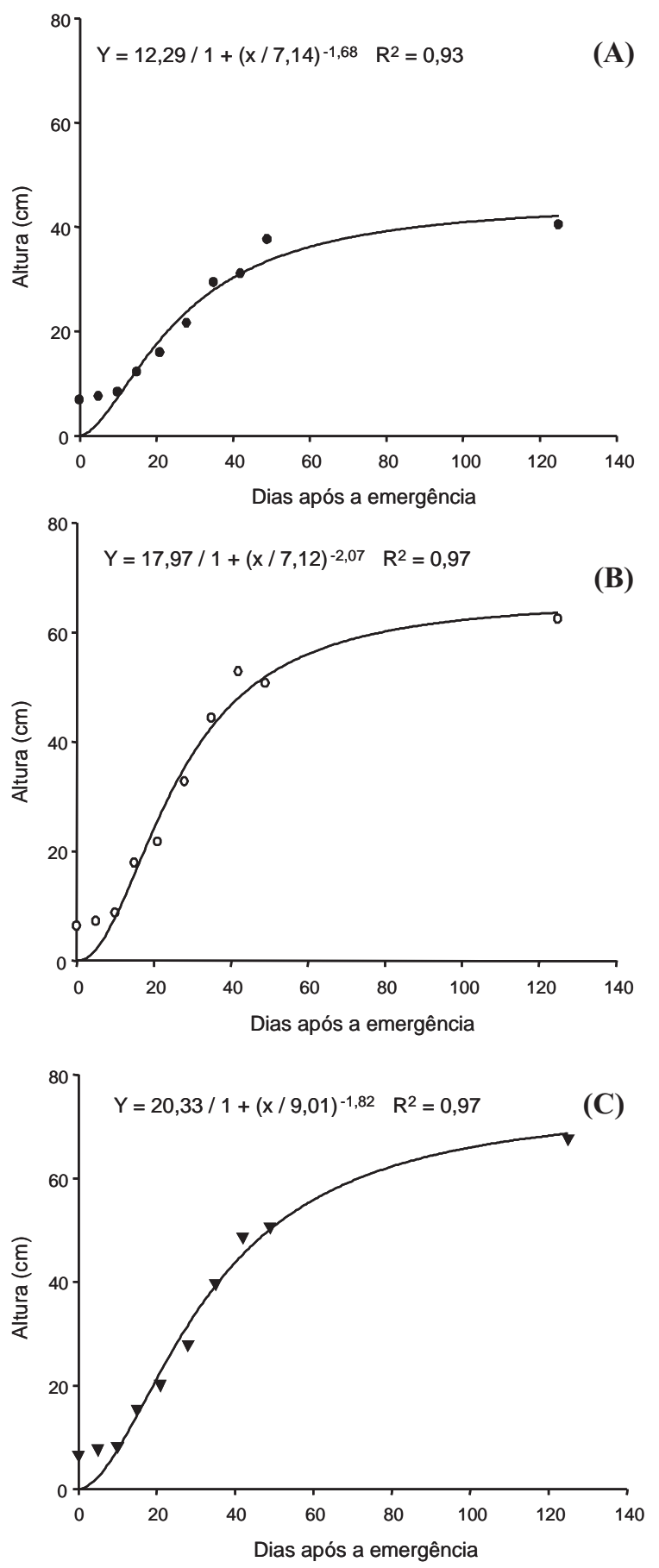

Figura 4 - Altura da soja, em função de períodos iniciais crescentes na presença de plantas daninhas em áreas de baixa (A), média (B) e alta infestação (C). 
densidade de plantas é aumentada, o potencial de fornecimento de recursos pelo ambiente se torna limitante, isto é, o rendimento passa a se tornar independente da densidade de
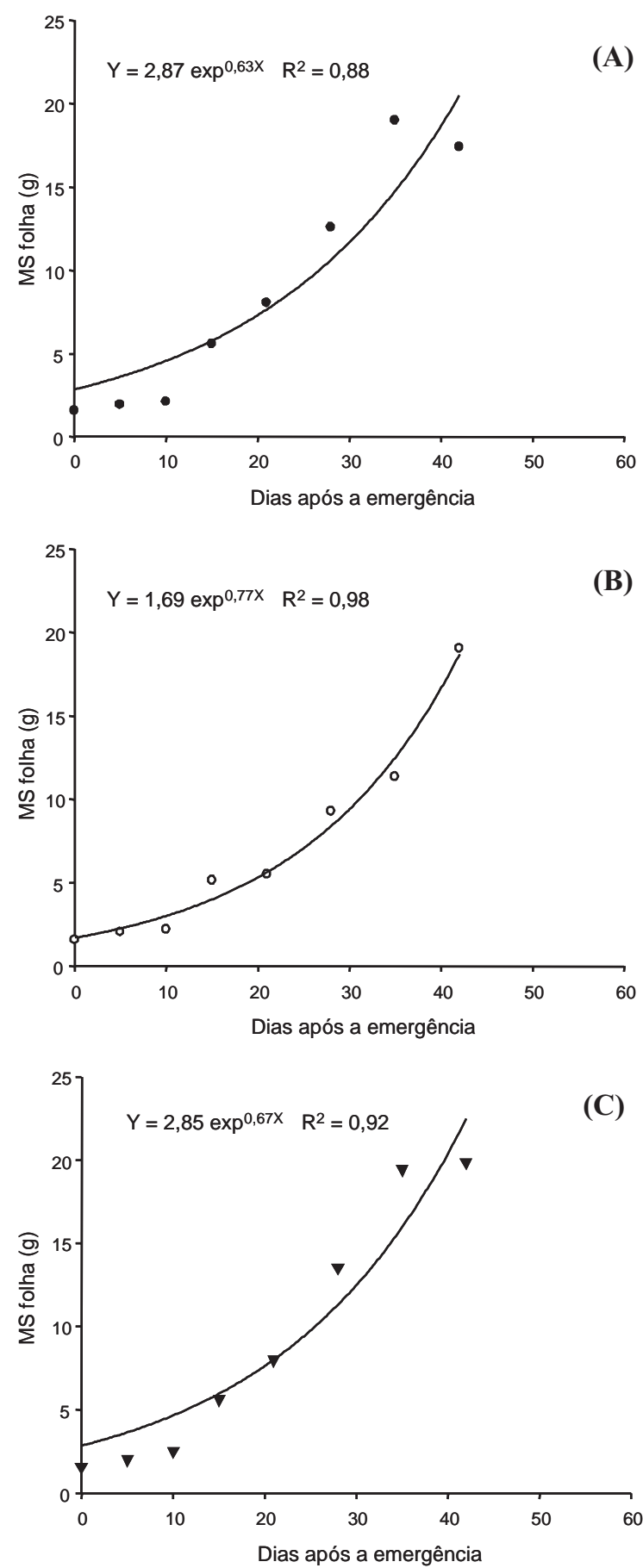

Figura 5 - Massa seca (MS) acumulada pelas folhas da soja, em função de períodos iniciais crescentes na presença de plantas daninhas em áreas de baixa (A), média (B) e alta infestação (C). plantas a partir de determinado nivel de infestação. Logo, a densidade de plantas encontradas até mesmo na área de baixa infestação deste experimento foi o suficiente para levar
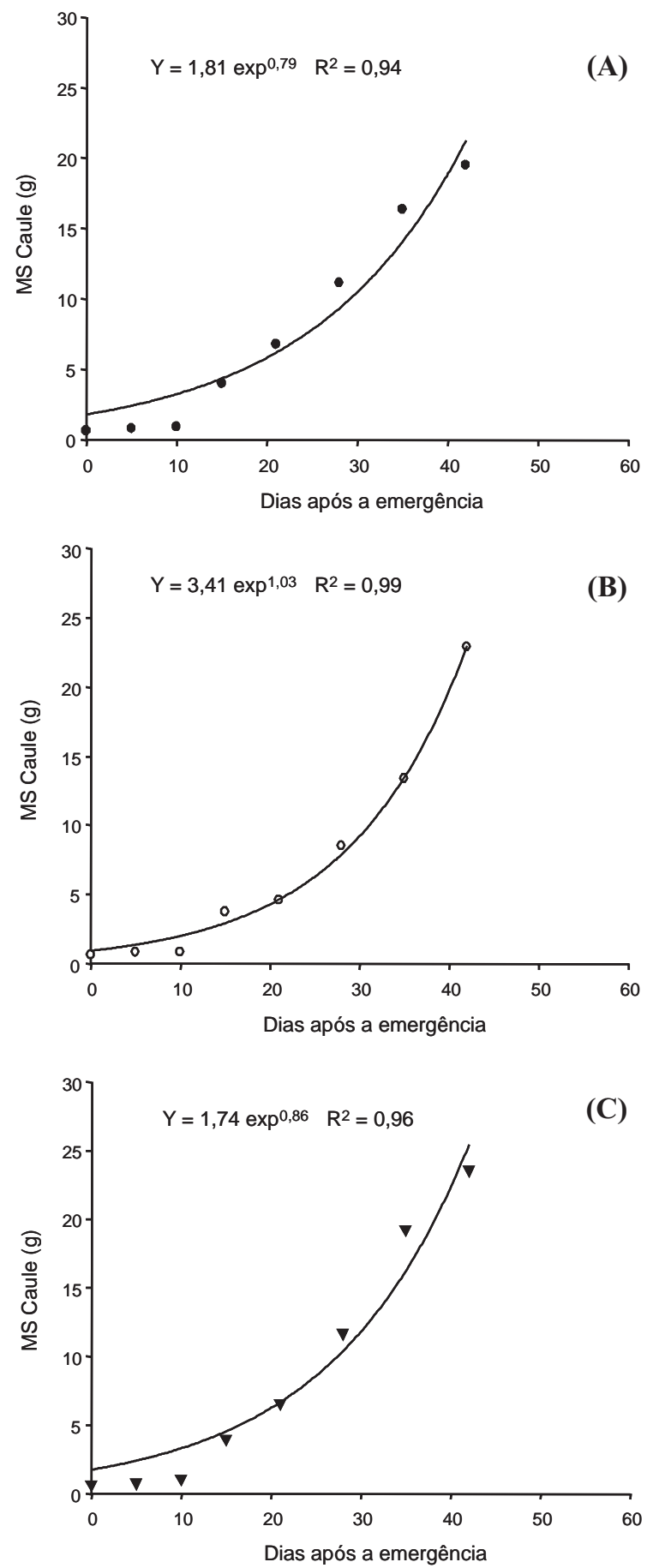

Figura 6 - Massa seca (MS) acumulada pelos caules das plantas de soja, em função de períodos iniciais crescentes na presença de plantas daninhas em áreas de baixa (A), média (B) e alta infestação (C).

Planta Daninha, Viçosa-MG, v. 27, n. 1, p. 75-84, 2009 
as plantas de soja ao estresse máximo em relação à capacidade de acúmulo de matéria seca. Avaliando a competição relativa de espécies de plantas daninhas com dois
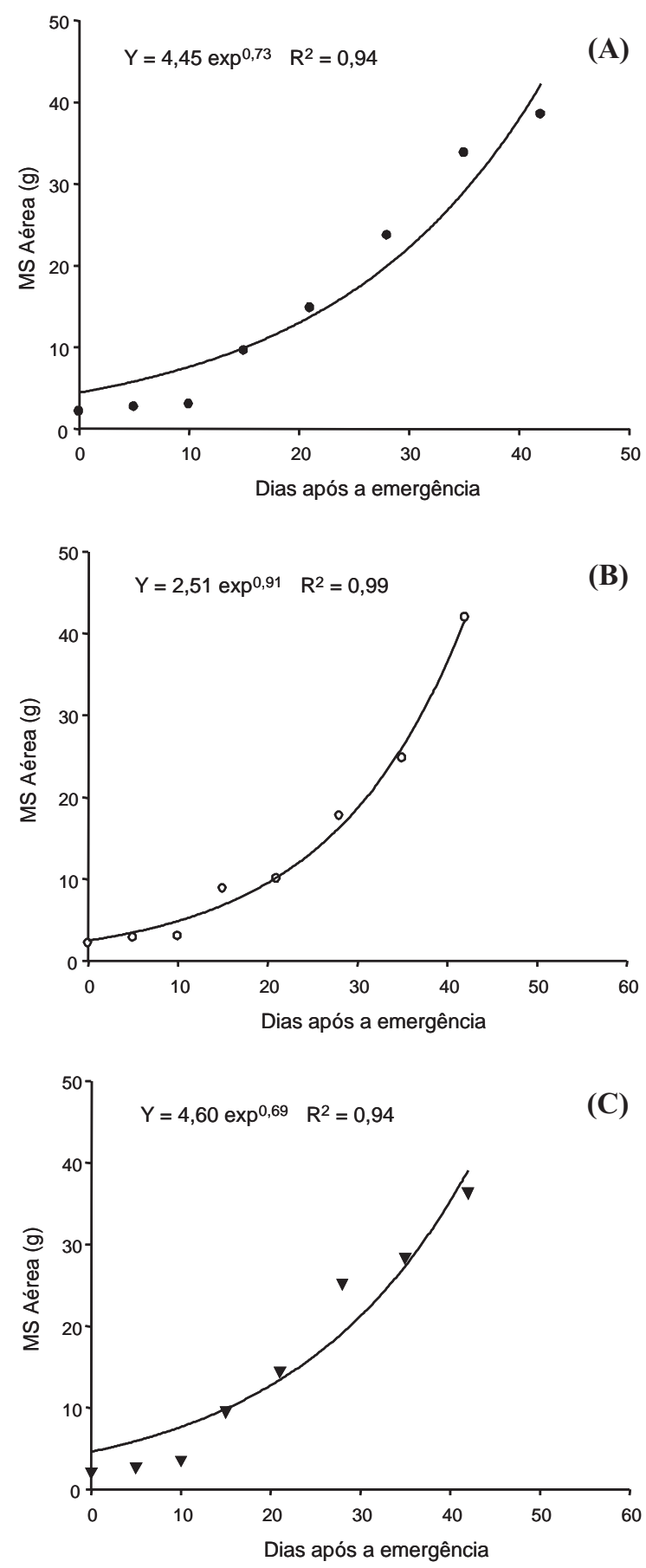

Figura 7 - Massa seca (MS) acumulada pelas partes aéreas da soja, em função de períodos iniciais crescentes na presença de plantas daninhas em áreas de baixa (A), média (B) e alta infestação (C). cultivares de soja (Embrapa-48 e Embrapa-62), considerou-se que em densidade de 10 plantas $\mathrm{m}^{-2}$ já ocorrem intensas reduções, ou seja, perdas que justificam o provável uso de herbicidas pela relação custo / benefício (Voll et al., 2002). O número de folhas (Figura 8) foi outra característica que não variou em função do nivel de infestação, apresentando crescimento linear ao longo do tempo.

Quanto à área foliar da soja (Figura 9), não foi observada diferença entre baixa e média infestação, indicando menor competição por luminosidade entre plantas da cultura e daninhas do que na área de alta infestação. Em geral, o incremento dessa variável é uma das maneiras de a planta aumentar a superficie fotossintética, assegurando aproveitamento mais eficiente das baixas intensidades luminosas e, conseqüentemente, compensando as baixas taxas de fotossintese por unidade da área foliar característica da folha de sombra (Jones \& McLeod, 1990). Além disso, o aumento dessa variável pelas plantas da cultura resulta em maior sombreamento da comunidade infestante, com conseqüente redução de sua capacidade competitiva, principalmente se as plantas daninhas sombreadas apresentarem metabolismo $\mathrm{C}_{4}$.

Na correlação entre as variáveis, é possível observar que todos os parâmetros avaliados atuam em conjunto e influenciam um ao outro de maneira proporcional, uma vez que foi observada interação significativa entre todos os pares de variáveis analisados (Tabela 1). Assim, a altura de plantas está diretamente relacionada com a massa de caule, folha, parte aérea, número de folhas e área foliar. Da mesma forma, plantas com maior área foliar apresentaram maior massa seca da parte aérea e de caule, indicando ganho geral de fotoassimilados pela planta, em razão da maior capacidade de interceptação de luz. O número de folhas também correlacionou-se diretamente com a área foliar. Dessa forma, a maior área foliar pode ser atribuída ao maior número de folhas, e não somente ao aumento de área das folhas já existentes na planta. É possivel inferir que as variáveis da parte aérea de plantas de soja atuam em conjunto no maior desenvolvimento de plantas de soja quando submetidas à competição. O estresse sofrido por sombreamento não se reflete apenas na área foliar, mas em todas as demais variáveis a ela associadas. 
Quando do estudo de plantas sob competição, torna-se mais importante o resultado da atuação em conjunto de todas as variáveis do que o comportamento de uma delas, por mais saliente que possa parecer em relação às demais.
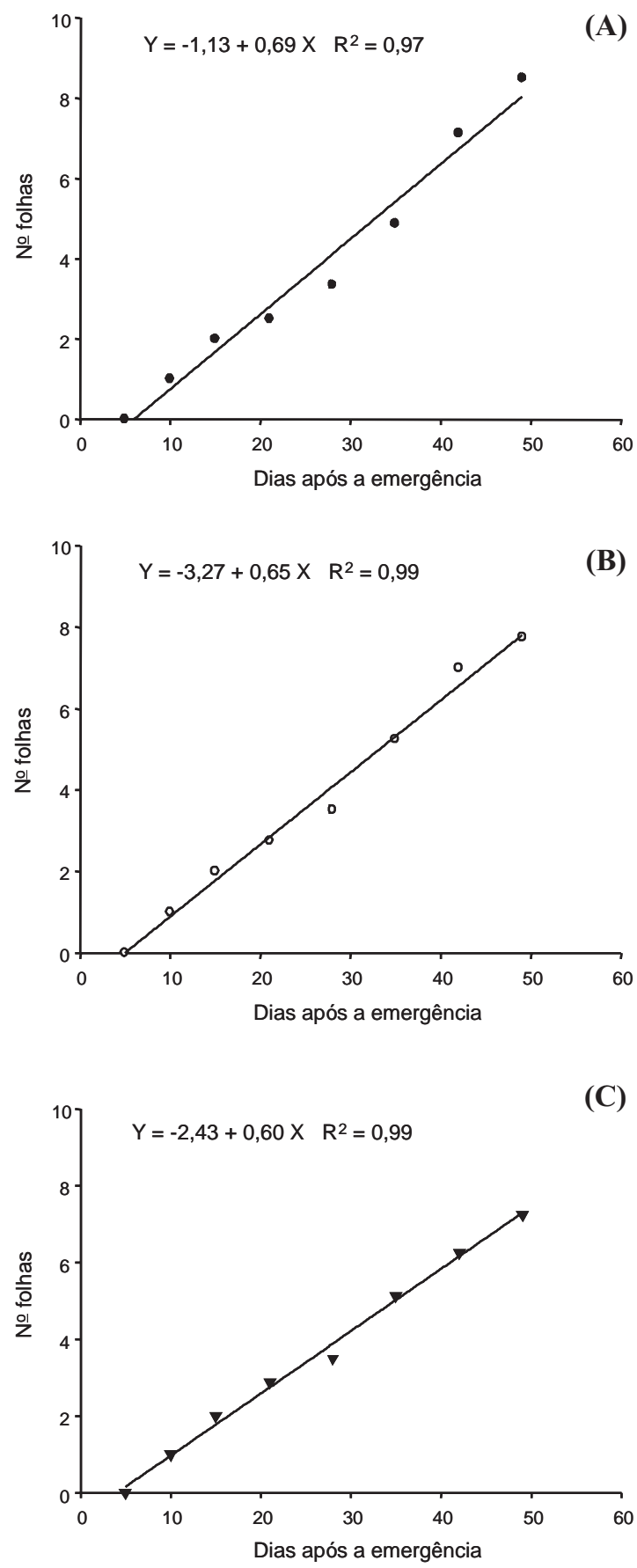

Figura 8 - Número (№) de folhas da soja, em função de períodos iniciais crescentes na presença de plantas daninhas em áreas de baixa (A), média (B) e alta infestação (C).
Com base nos resultados deste trabalho, conclui-se que tanto o período de convivência soja/plantas daninhas como o nivel de infestação da área influenciam as variáveis definidoras do crescimento da cultura da soja e que
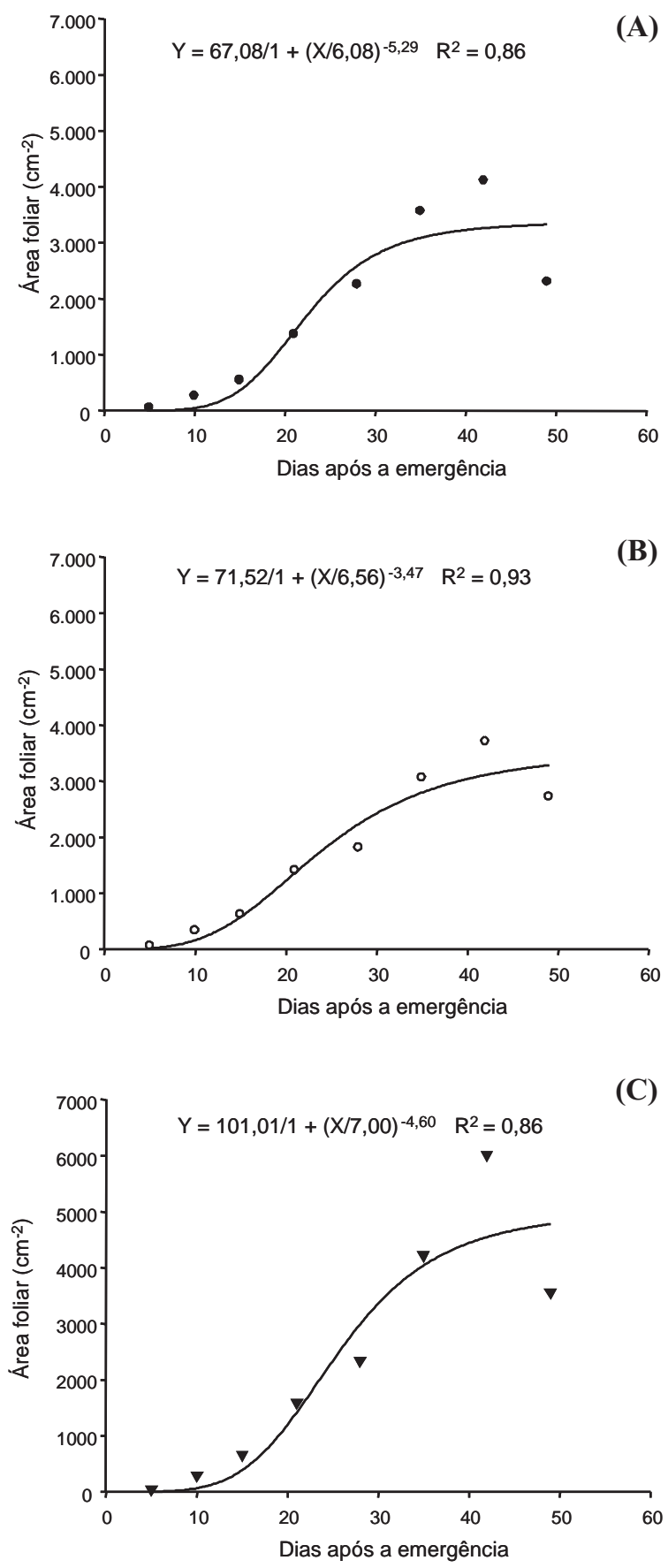

Figura 9 - Área foliar da soja, em função de períodos iniciais crescentes na presença de plantas daninhas em baixa (A), média (B) e alta infestação (C).

Planta Daninha, Viçosa-MG, v. 27, n. 1, p. 75-84, 2009 
Tabela 1 - Matriz de correlação linear de Pearson entre as variáveis: altura de plantas, massa seca dos ramos desprovidos de folhas, massa seca das folhas e dos ramos, número de folhas e área foliar

\begin{tabular}{|l|c|c|c|}
\hline \multicolumn{1}{|c|}{ Variável } & Interação & Variável & Interação \\
\hline ALT x MS CAULE & $0,81^{* *}$ & MS CAULE x ÁREA FOL & $0,86^{* *}$ \\
\hline ALT x MS FOLHA & $0,80^{* *}$ & MS CAULE x MS AÉREA & $0,99^{* *}$ \\
\hline ALT x MS ÁREA & $0,82^{* *}$ & MS FOLHA x MS AÉREA & $0,98^{* *}$ \\
\hline ALT x N- FOLHA & $0,90^{* *}$ & MS FOLHA x No- FOLHA & $0,90^{* *}$ \\
\hline ALT x ÁREA FOL & $0,79^{* *}$ & MS FOLHA x ÁREA FOL & $0,90^{* *}$ \\
\hline MS CAULE x MS FOL & $0,94^{* *}$ & ÁREA FOL x No FOLHA & $0,84^{* *}$ \\
\hline MS CAULE x No FOLHA & $0,85^{* *}$ & ÁREA FOL x MS AÉREA & $0,89^{* *}$ \\
\hline
\end{tabular}

** interação significativa a $1 \%$ de probabilidade pela matriz de Pearson.

em condições de lavoura deve-se minimizar tanto o nível de infestação da área quanto o período de convivência entre a cultura e as plantas daninhas, por meio do correto planejamento no momento do controle, da técnica utilizada para tal fim e da densidade populacional das plantas da cultura em função da infestação da área.

\section{LITERATURA CITADA}

BALLARE, C. L.; CASAL, J. J. Light signals perceived by crop and weed plants. Fields Crops Res., v. 67, n. 2, p. $149-160,2000$.

BUZATTI, W. J. S. Controle de plantas daninhas no sistema plantio direto na palha. In: PAULETTI, V.; SEGANFREDO, R. Plantio direto: atualização tecnológica. São Paulo: Fundação Cargill/Fundação ABC, 1999. p. 97-111.

FERREIRA, F. A. et al. Manejo integrado de plantas daninhas em hortaliças. In: MANEJO integrado de doenças, pragas e plantas daninhas. Viçosa, MG: Universidade Federal de Viçosa, 2000. p. 365-372

GHERSA, C. M.; HOLT, J. S. Using phenology prediction in weed management: A review. Weed Res., v. 35, n. 6, p. $461-470,1995$.

GODOY, G.; VEGA, J.; PITTY, A. El tipo de labranza afecta la flora y la distribución vertical del banco de semillas de malezas. Ceiba, v. 36, n. 2, p. 217-229, 1995.

JAKELAITIS, A. et al. Dinâmica populacional de plantas daninhas sob diferentes sistemas de manejo nas culturas de milho e feijão. Planta Daninha, v. 21, n. 1, p. 71-79, 2003.

JONES, R. H.; MACLEOD, K. W. Growth and photosynthetic responses to a range of light environments in chinese tollow tree and carolina ash seedlings. For. Sci., v. 36, n. 4, p. 851-862, 1990.

LAMEGO, F. P. et al. Tolerância a interferência de plantas competidoras e habilidade de supressão por cultivares de soja - I. Resposta de variáveis de crescimento. Planta Daninha, v. 23 , n. 3 , p. $405-414,2005$.
MELGES, E.; LOPES, N. F.; OLIVA, M. A. Crescimento e conversão da energia solar em soja cultivada sob quatro níveis de radiação solar. Pesq. Agropec. Bras., v. 24, n. 9 , p. $1065-1072,1989$

MELO, H. B. et al. Interferência das plantas daninhas na cultura da soja cultivada em dois espaçamentos entre linhas. Planta Daninha, v. 19, n. 2, p. 187-191, 2001.

PITELLI, R. A. Interferência de plantas daninhas em culturas agrícolas. Inf. Agropec., v. 11, n. 129, p. 19-27, 1985

PROCÓPIO, S. O. et al. Absorção e utilização do fósforo pelas culturas da soja e do feijão e por plantas daninhas. R. Bras. Ci. Solo, v. 29, n. 3, p. 911-921, 2005

RADOSEVICH, S. R..; HOLT, J.; GHERSA, C. Weed ecology: implications for management. 2.ed. New York: John Wiley \& Sons, 1997. 589 p.

RAJAN, I.; SWANTON, C. L. Understanding maize-weed competition, light quality and the whole plant. Fields Crops Res., v. 71, n. 2, p. 139-150, 2001.

RIZZARDI, M. A. et al. Perdas de rendimento de grãos de soja causadas por interferência de picão-preto e guanxuma. Ci. Rural, v. 33, n. 4, p. 621-627, 2003.

SANTOS, J. B. et al. Captação e aproveitamento da radiação solar pelas culturas da soja e do feijão e por plantas daninhas. Bragantia, v. 62, n. 1, p. 147-153, 2003

SILVA, A. A. et al. Aspectos fitossociológicos da comunidade de plantas daninhas na cultura do feijão sob diferentes sistemas de preparo do solo. Planta Daninha, v. 23, n. 1, p. 17-24, 2005.

SILVA, A. A.; SILVA, J. F. Tópicos em manejo integrado de plantas daninhas. Viçosa, MG: Universidade Federal de Viçosa, 2007.

TAIZ, L.; ZEIGER, E. Fisiologia vegetal. Porto Alegre: Artmed, 2004. 720 p.

VANDEVENDER, K. W.; COSTELLO, T. A.; SMITH JR., R. $\mathrm{J}$. Model of rice (Oryza sativa) yield reduction as a function of weed interference. Weed Sci., v. 45, n. 2, p. 218-224, 1997.

VOLL, E. et al. Competição relativa de plantas daninhas com dois cultivares de soja. Planta Daninha, v. 20, n. 1, p. 17-24, 2002. 